\title{
A CULTURA CONJUGAL, FAMILISMO JURÍDICO E A JUDICIALIZAÇÃO DE DIREITOS LGBTI
}

\author{
Brendhon Andrade Oliveira ${ }^{1}$
}

Resumo: O presente estudo analisa o processo de reconhecimento do direito à homoconjugalidade, por intermédio de análise documental que selecionou propostas legislativas e sentenças judiciais. Utiliza-se do método hipotético-dedutivo considerando três hipóteses principais: existe uma centralidade da família no ordenamento jurídico brasileiro; a luta por reconhecimento em matéria de família é uma busca por legitimidade e também por acesso a bens e direitos sociais; e restou a judicialização da família como alternativa à resistência legislativa em reconhecer os direitos LGBTI. Realizou-se estudo bibliográfico a partir dos estudos jurídicos, feministas, queer, gays e lésbicos. Assim, identifica que o desejo de constituir família é complexo e multifacetado, uma vez que há atravessamentos sociais pela cultura conjugal, a centralidade da família nas políticas de proteção social e o direito civil como vetor de direitos sociais, enfrentando, ainda, resistências conservadoras na política majoritária recorrendo-se à judicialização como estratégia de reconhecimento jurídico de casais gays-lésbicos.

Palavras-chave: Direito de Família; Casamento; Poder Judiciário; Política Institucional; Conservadorismo.

\section{INTRODUÇÃO}

Pesquisas e estudos anteriores têm demonstrado a presença de uma 'ofensiva antigênero' na arena política brasileira. Esse termo denomina o conservadorismo que tem se utilizado de pânicos morais e ódio contra mulheres, lésbicas, gays, bissexuais, travestis, transexuais e intersexo (LGBTI), e no âmbito das instituições democráticas tem atuado contrariamente à aprovação de direitos sexuais e reprodutivos, sob argumentos de que a

\footnotetext{
${ }^{1}$ Mestrando em Direito pela Universidade Federal de Mato Grosso (PPGD/UFMT). Graduação em Direito pela Universidade Federal do Tocantins (UFT). Membro do Núcleo de Estudos e Pesquisa Sobre a Organização da Mulher e Relações de Gênero (Nuepom/UFMT). andradebrendhon@ gmail.com
}

Vol. 03, N. 10, Abr. - Jun., 2020 - http://periodicoscientificos.ufmt.br/ojs/index.php/rebeh/index 


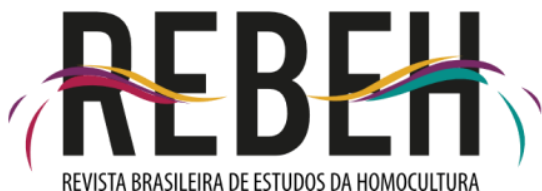

'ideologia de gênero' e casamento de casais gays e lésbicos tem destruído as bases da família tradicional e da moral cristã hegemônica. Isso tem resultado na judicialização como forma de satisfação dos direitos da comunidade LGBTI (IRINEU et al, 2019; OLIVEIRA e LEAL, 2020; IRINEU e OLIVEIRA, 2020; LEAL e OLIVEIRA, 2020).

Centrando-se no tema da homoconjugalidade e direitos de família, compreendese que conhecer o processo de reconhecimento dos casais gays-lésbicos no contexto brasileiro, que é marcado pela centralidade da família - tanto como pauta central na agenda conservadora anti-LGBTI, quanto no ordenamento jurídico pátrio - é de fundamental importância para compreender o lugar, os limites e as possibilidades na relação do movimento de LGBTI com a institucionalidade brasileira.

Nesse sentido, o objetivo central desse trabalho é analisar o processo de reconhecimento da família homossexual no Brasil. Portanto, elenca-se os seguintes específicos: mapear no ordenamento jurídico brasileiro os direitos decorrentes da instituição família; verificar o processo de participação da comunidade LGBTI e suas disputas na arena política; e por fim, avaliar o processo de judicialização e reconhecimento da conjugalidade homossexual.

A pesquisa utiliza-se do método hipotético-dedutivo, ao qual "o pesquisador elege o conjunto de proposições hipotéticas que acredita serem viáveis como estratégia de abordagem para se aproximar de seu objeto" (MEZZAROBA; MONTEIRO, 2009, p. 68). Nesse sentido, as hipóteses assumem a forma de partida que deverão ser verificadas no decorrer da pesquisa.

Considerando o exposto, parte-se da hipótese de que há uma centralidade da família imbuída no ordenamento jurídico brasileiro tendo em vista o tratamento especial da matéria no Código Civil brasileiro e ainda os dispositivos relacionados esparsos na Constituição de 1988 e legislação infraconstitucional.

A segunda hipótese é de que a luta por reconhecimento LGBTI nas questões de família constitui dupla finalidade. A primeira é a busca pela normalização e legitimidade, aquilo que Vespucci (2014, p. 31) descreve como o atravessamento de "uma noção cultural marginal a uma noção hegemônica para representar determinadas relações sexo- 
afetivas", enquanto que a segunda seria o acesso a direitos derivados da instituição família para além do direito civil, considerando também de outras naturezas.

A última hipótese considera que a judicialização da homoconjugalidade se coloca como alternativa de reconhecimento dos direitos LGBTI, dadas as negociações políticas infrutíferas, chamando o Supremo Tribunal Federal para decidir essa questão não pacificada na arena política.

A pesquisa possui caráter qualitativo, na qual preponderará o "exame rigoroso da natureza, do alcance e das interpretações possíveis para o fenômeno estudado e (re)interpretado de acordo com as hipóteses [...] estabelecidas" (MEZZAROBA; MONTEIRO, 2009, p. 110).

Enquanto procedimentos técnicos, emprega-se a análise documental como técnica de coleta de dados, tendo em vista "a importância dessa estratégia como alternativa de investigação dadas as contribuições que uma análise crítica e aprofundada de determinados documentos pode aportar" (PRATES e PRATES, 2009, p. 120).

Nesse caminho, o mapeamento dos direitos decorrentes da instituição familiar no ordenamento jurídico brasileiro selecionou os seguintes documentos: a Constituição Federal, o Código Civil, o Código Penal, a Lei 8.112 de 1990 e a Lei no 8.742 de 1993. Para avaliação da judicialização da homoconjugalidade, selecionou-se a Ação Direta de Inconstitucionalidade 4.277 do Distrito Federal, que fora apreciada pelo Supremo Tribunal Federal em 2011. Integra o corpus desse estudo, ainda, as proposições legislativas acerca da homoconjugalidade.

Por fim, entre os/as teóricos/as basilares deste estudo encontram-se colaborações de Michel Foucault, Luiz Mello, Maria Berenice Dias, Judith Butler, Luis Roberto Barroso, Renata Hiller, Shelley Budgeon, Guillermo Sunkel, dentre outros/as.

\section{A CENTRALIDADE DA FAMÍLIA NO ORDENAMENTO JURÍDICO}

O presente tópico tem a finalidade de discutir (a) a família e a cultura conjugal, enquanto construções sociais que afetam a organização social, o Estado e o direito; (b) a legislação civil do direito de família e suas interlocuções constitucionais e penais; e (c) 


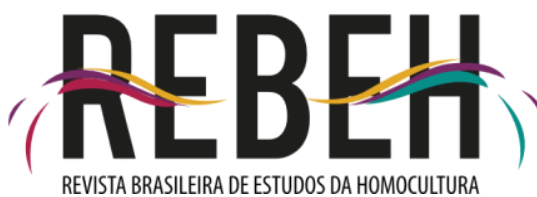

as políticas de proteção social, destacando-se o tripé da seguridade social (assistência, previdência e saúde).

\subsection{A família e a cultura conjugal}

Ariés (1986, p. 210), em seus estudos sobre a história da família, identifica que essa instituição é moldada pelas variáveis espaço-tempo, sendo o modelo hegemônico da atualidade resultado de construções sócio-históricas. A partir de uma análise iconográfica, o autor concluiu que "o sentimento de família era desconhecido da Idade Média e nasceu nos séculos XV-XVI, para se exprimir com um vigor definitivo no século XVII".

O nascimento e desenvolvimento do sentimento de família "se formou em torno da família conjugal, a família formada pelos pais e seus filhos" (ARIÈS, 1986, p. 223). A família conjugal moderna ganhou espaço em detrimento do modelo familiar da Idade Média, na qual prevaleciam a linhagem e a indivisão da integridade patrimonial.

Em sua análise, Ariès (186, p. 214) nota que, apesar desse modelo emergente valorizar a intimidade, identidade e o sentimento, as desigualdades a partir das diferenças também constituem os pilares da família moderna, tendo em vista que "essa evolução reforça os poderes do marido, que acaba por estabelecer uma espécie de monarquia doméstica".

Acerca da história da sexualidade, Foucault (1988, p. 103) compreende que houve a "fixação do dispositivo de aliança e do dispositivo de sexualidade na forma de família". Portanto, "a família é o permutador da sexualidade com a aliança: transporta a lei e a dimensão do jurídico para o dispositivo da sexualidade; e a economia do prazer e a intensidade das sensações para o regime da aliança".

Para Foucault (1988), o poder se exerce sobre o sexo em todas as dimensões, identificando uma força geral de poder, que é o direito, no qual "de qualquer modo se esquematiza o poder sob uma forma jurídica e se definem seus efeitos como obediência" (FOUCAULT, 1988, p. 82). A partir dos estudos do autor, percebe-se que o direito tem um papel fundamental na regulação do dispositivo da sexualidade e serve como instrumento de reconhecimento, estabelecimento e legitimação daquilo que foi convencionado como normal socialmente.

Vol. 03, N. 10, Abr. - Jun., 2020 - http://periodicoscientificos.ufmt.br/ojs/index.php/rebeh/index 


\section{员드댄}

Nessa esteira, Rubin (2012, p. 15) aponta que "todos os comportamentos eróticos são considerados maus a menos que uma razão específica para isentá-lo tenha sido estabelecida. As mais aceitas desculpas são o casamento, a reprodução e o amor". A autora buscou alertar que o exercício da sexualidade bom, saudável e legitimo encontrase restrito à aliança, ou seja, dentro de uma lógica de casamento e família.

Diversos estudos vêm apontando para uma força ideológica da cultura conjugal (Budgeon, 2008; Hiller, 2012). Essa força seria a fixação do relacionamento de casal monogâmico no centro do exercício normativo da sexualidade, sustentada pela ideologia do casamento e família.

Esta se manifesta duplamente, primeiramente, como um desejo construído e difundido socialmente de que as pessoas necessitam do casamento, na qual a relação afetivo-sexual com um parceiro/a é mais importante e que aqueles/as casados/as são mais felizes e satisfeitos/as, e em segundo, que "o matrimônio, mais que um direito em si mesmo, constitui histórica e atualmente um vetor de acesso a outros bens sociais" (HILLER, 2012, p. 95, tradução nossa²).

Budgeon (2008) aponta que as críticas à heterossexualidade são necessárias para questionar o "natural" e o "normal", na qual um dos objetivos da heteronormatividade seria a organização da vida íntima através de um relacionamento de casal. Para a autora, essa cultura privilegia o casal como sendo o coração da formação social, evidenciando a problemática produzida pela falta de reconhecimento social que estão submetidas aquelas relações não conformes à heteronormatividade ${ }^{3}$.

Nesse sentido, "as possibilidades de reivindicar pertencer ao social residem na relação com as práticas e instituições nas quais a heteronormatividade é imanente" (BUDGEON, 2008, p. 306, tradução nossa ${ }^{4}$ ). As convenções sociais criam expectativas sobre os indivíduos e seus projetos devem privilegiar a formação de família.

\footnotetext{
2 “[...] el matrimonio, más que un derecho en sí mismo, constituye histórica y actualmente un vector de acceso a otros bienes sociales" (HILLER, 2012, p. 95).

${ }^{3}$ Termo utilizado pela autora para se referir a produção ideológica da heterossexualidade com individual, natural e universal. Não se refere à pratica da heterossexualidade em si, mas das estruturas e instituições que a tornam coerente e privilegiada frente as outras possibilidades (BUDGEON, 2008).

4 "The possibilities for making claims to belonging to the social reside in one's relationship to the practices and institutions in which heteronormativity is immanent" (BUDGEON, 2008, p. 306)
}

Vol. 03, N. 10, Abr. - Jun., 2020 - http://periodicoscientificos.ufmt.br/ojs/index.php/rebeh/index 


\section{REBE员}

Além disso, "historicamente, a solidão operou com status marginalizado enquanto que casais heterossexuais ocupam posição privilegiada, posição que confere aos seus habitantes uma gama de recompensas sociais, econômicas e simbólicas" (BUDGEON, 2008, p. 301, tradução nossa ${ }^{5}$ ).

Corroborando com o exposto, Hiller (2012, p. 97, tradução nossa ${ }^{6}$ ) entende que o matrimônio assume a posição de injetar normalidade a vida e é utilizado como estratégia "para estar em ordem com a sociedade, ter filhos e obter recursos da legitimidade social".

Nesse cenário, o matrimonio é mais que direito, é uma das obrigações da/o cidadã/o. As relações matrimoniais servem como instrumento de regulação entre as pessoas e também entre elas e o Estado, intervindo na condição de cidadania, tendo em vista que alguns bens e direitos são acessados através de vínculos matrimoniais.

A heterossexualidade foi instituída como única possibilidade de exercício da sexualidade normal que deve ser praticada dentro da lógica de família, monogâmica e reprodutiva. Esse modelo fora assumido pela forma jurídica que protege e determina os direitos e deveres decorrentes da instituição familiar. A força ideológica da cultura conjugal, incentiva e privilegia os relacionamentos de casais, se alinhando à heteronormatividade.

Uma vez que se encontra no topo da pirâmide social, esse arranjo de família reproduz diversas desigualdades. Entre elas o acesso à justiça e ao direito, afeta a proteção daqueles que não possuem um projeto de casamento para sua vida privada, bem como aqueles/as que escapam à heterossexualidade como expressão de orientação sexual. Embora o sistema de justiça brasileiro tenha buscado estender sua proteção jurídica para além da família nuclear (pai, mãe e filhos), encontra grandes desafios e dificuldades em desvincular desse modelo hegemônico.

\footnotetext{
5 "Historically singleness has operated as a marginalized status while heterosexual couples have occupied a privileged position that confers upon its inhabitants a range of social, economic and symbolic rewards" (BUDGEON, 2008, p. 301).

${ }^{6}[\ldots]$ para estar en orden con la sociedad, para tener hijos y obtener recursos de la legitimidad social. [...] el matrimonio, más que un derecho, parece constituir una de las obligaciones del ciudadano (HILLER, 2012, p. 97)
}

Vol. 03, N. 10, Abr. - Jun., 2020 - http://periodicoscientificos.ufmt.br/ojs/index.php/rebeh/index 


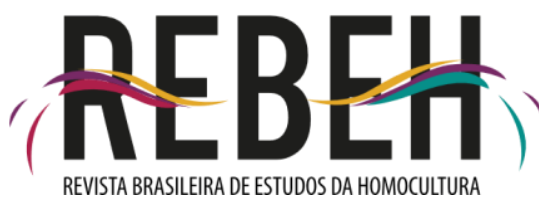

\subsection{Analisando o direito de família}

Anteriormente ao advento da República, só havia casamento religioso no Brasil para os adeptos do catolicismo, o que influenciou a forma do casamento civil que veio a ser regulamentado em 1891. O Código Civil de 1916 reduzia a família ao casamento, que | 13 à época era impedido de dissolução e discriminava casais e filhos fora desse arranjo.

Dias (2016, p. 208) aponta que a lei se referia ao perfil de uma família "matrimonializada, patriarcal, hierarquizada, patrimonializada e heterossexual", e era caracterizada pela chefia masculina restando aos filhos e esposa a obediência hierárquica. As mulheres se tornavam relativamente capazes ${ }^{7}$, não podendo trabalhar e nem administrar bens.

O objetivo da família civil era a conservação do patrimônio - até porque essa é a finalidade maior do direito privado. Quanto à dissolução, havia a figura sui generis do desquite, que, entretanto, não dissolvia o vínculo matrimonial, embora fosse possível a anulação do casamento em caso de desvirginamento da mulher (DIAS, 2016).

Desde então algumas mudanças começaram a atravessar o direito de família, como a Lei 4.121 de 1962, o Estatuto da Mulher Casada, que devolvia às mulheres casadas a plena capacidade e também a instituição do divórcio em 1977 com Emenda Constitucional 9/77 e Lei 6.615/77. Ressalta-se que, através da judicialização, as relações extramatrimoniais obtiveram reconhecimento na jurisprudência pátria.

A Constituição Federal de 1988, numa conjuntura pós-ditadura militar, preocupou-se com inúmeros direitos civis, políticos e sociais, e em relação à família, concedeu um lugar especial como se extrai do título VI: "Art. 226. A família, base da sociedade, tem especial proteção do Estado" (BRASIL, 1988). O termo família é repetido 27 vezes no texto magno.

Dias (2016, p. 32) avalia que o constituinte buscou alargar o conceito de família, afastando a ideia de casamento como pressuposto da família. A Constituição Federal inova ao conceder juridicidade aos relacionamentos extramatrimoniais, incorpora a união

\footnotetext{
${ }^{7}$ Se refere à capacidade para praticar atos da vida civil. Com o $\mathrm{CC} / 17$, a capacidade civil de mulheres casadas estava vinculada ao marido.
}

Vol. 03, N. 10, Abr. - Jun., 2020 - http://periodicoscientificos.ufmt.br/ojs/index.php/rebeh/index 


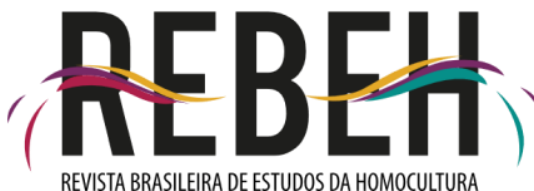

estável e a monoparentalidade (um dos pais com filhos/as) e inaugura o conceito de entidade familiar.

O Código Civil de 2002, vigente atualmente, não deu passos ousados nem em relação as novidades e pluralismo da recente Constituição, e "trata quase que exclusivamente de uma modalidade de família: a constituída pelo casamento" (DIAS, 2016, p. 16). Essa 'nova' regulamentação do direito de família(s) acabou por reiterar preconceitos e desigualdades, como a referência entre homem e mulher.

O CC/2002 não buscou delinear os conceitos de família, entidade familiar ou alguma modalidade de família, buscando apenas enumerar uma porção de institutos que regulamentam algum tipo de vínculo sanguíneo e/ou afetivo. Assim sendo, o novo Código buscou regular as relações de filiação e parentesco, bem como a união estável e o casamento. Este último de forma privilegiada, reunindo 110 artigos disciplinando a celebração, direitos e deveres dos cônjuges, regime de bens e dissolução (DIAS, 2016).

Destaque para os artigos 1.514, acerca do casamento, e 1.723, acerca da união estável, ambos do Livro do Direito de Família, do Código Civil de 2002:

\footnotetext{
Art. 1.514. O casamento se realiza no momento em que o homem e a mulher manifestam, perante o juiz, a sua vontade de estabelecer vínculo conjugal, e o juiz os declara casados.

Art. 1.723. É reconhecida como entidade familiar a união estável entre o homem e a mulher, configurada na convivência pública, contínua e duradoura e estabelecida com o objetivo de constituição de família. (BRASIL, 2002)
}

Considerando o exposto, a Constituição Cidadã preocupou-se com a promoção de direitos de inúmeras ordens, dado o longo período de violação de direitos humanos e fundamentais no período ditatorial antecedente. Há a constitucionalização do direito civil, incluídos os direitos de família, destacando-se as novas modalidades da monoparentalidade e união estável, contribuindo para um alargamento da proteção jurídica destinada à família.

Não obstante, ressalta-se que o Código Civil não disciplinou os vínculos monoparentais mesmo advindo 14 anos após a CF/88. Acerca da união estável, de pouco serviu a especial proteção conferida pela Carta Magna, uma vez que leis extravagantes que trataram de habitação e sucessões, por exemplo, basicamente foram reproduzidas pelo CC/02.

Vol. 03, N. 10, Abr. - Jun., 2020 - http://periodicoscientificos.ufmt.br/ojs/index.php/rebeh/index 


\section{奋ᄃBE吕}

Além disso, "em que pese a equiparação constitucional, a lei civil, de forma retrógrada e equivocada, outorgou à união estável tratamento notoriamente diferenciado. Em três escassos artigos (CC 1.723 a 1.726) disciplina seus aspectos pessoais e patrimoniais". Destaca-se que o "direito dos conviventes à adoção está condicionado à prova da estabilidade da família (ECA $42 \S 2 .^{\circ}$ e 197-A III), exigência que não é feita aos casados" (DIAS, 2016, p. 385).

Esses dados revelam que, mesmo após alargamentos e avanços históricos na regulação jurídica da família, o casamento mantém sua posição de hierarquia e privilégio em relação as demais modalidades. Inclusive o instituto do casamento é utilizado como parâmetro para os novos arranjos e modalidades, embora sua normatização e concepções sejam insuficientes para tratar das famílias contemporâneas em sua pluralidade.

Quando o Código Civil de 2002 foi aprovado, havia projetos com fins a reconhecer a união entre pessoas do mesmo sexo no Poder Legislativo, bem como ações judicializando o direito de participar no regime geral de previdência do parceiro. Todavia, optaram por manter a referência a 'um homem e uma mulher', dispositivos esses que serviram por muito tempo de justificativa para negar proteção jurídica às uniões de pessoas do mesmo sexo como entidade familiar.

Há que se apontar, ainda, que o processo constituinte de 1986/87 contou mobilizações dos movimentos de diversidade sexual para incluir expressamente o termo orientação sexual no artigo $3^{\circ}$, IV, que se refere a não-discriminação.

A proteção à família não se encontra presente apenas na CF/88 e CC/02. O Código Penal de 1940 possui um título, em sua parte especial, que trata dos crimes contra a família. Destaca-se, em especial, que aparece também no texto constitucional e civil: a questão da monogamia. $\mathrm{O}$ art. 235 do CP/1940 é expresso em criminalizar aquele/a que "contrair alguém, sendo casado, novo casamento: pena - reclusão, de dois a seis anos", contestando o princípio da intervenção mínima e o emblema do direito penal como ultima ratio.

No CC/2002 a questão aparece nos artigos 1.521 VI, que prevê o impedimento das pessoas casadas de casar, e 1.548 II e $1.521 \mathrm{VI}$, que a bigamia torna nulo o casamento. Acerca do art. 1.727, "se esforça o legislador em não emprestar efeitos jurídicos às 


\section{슈드댄}

relações não eventuais entre o homem e a mulher impedidos de casar, chamando-as de concubinato" (DIAS, 2016, p. 44).

A família hegemônica é caracterizada pela heterossexualidade, a reprodução e a monogamia e o Estado tem interesse em manter esse arranjo a ponto de privilegiá-lo no ordenamento jurídico. A monogamia está relacionada à propriedade privada e se revela na preocupação com questões patrimoniais e econômicas, além de implicar também no sistema moral religioso cristão. Todavia, não cabe ao Estado se apropriar deste local de interdição (DIAS, 2016).

\subsection{O familismo nos direitos e políticas de proteção social}

À família se destina papel central nas políticas de proteção social na América Latina, uma vez que os sistemas de seguridade deram ênfase na redistribuição como compensação das desigualdades sociais (SUNKEL, 2006). Nos anos 1980, o Estado era o protagonista na provisão de serviços sociais, buscando-se estabelecer o regime de bemestar social, almejando o desenvolvimento. $\mathrm{O}$ autor caracterizou este regime como "familista", uma vez que combinava a proteção social para o homem provedor com a terceirização da proteção e responsabilidade pelo bem-estar à família.

Nos anos 1990, o Estado perde protagonismo e o mercado surge como um terceiro pilar, dada a intenção de aceleração do crescimento econômico. Orientou-se a política social para adoção das reformas de mercado, onde o setor privado teria, assim, um papel importante na prestação de serviços de educação, saúde e previdência. A condução familista se mantém, visto que as mulheres incorporaram ao mercado de trabalho e ainda havia um deslocamento para as famílias das provisões anteriormente fornecidas pelo Estado (SUNKEL, 2006).

O pensamento de Sunkel (2006) chama a atenção para a distribuição de responsabilidades sociais entre Estado, família e mercado, no qual a política social tem sido orientada pela compreensão da família tanto por ser lugar de resolução de necessidades sociais, quanto por ser intermediadora no acesso aos direitos. No contexto brasileiro, a respeito das políticas sociais, Mioto (2004, p. 3) entende que 
A capacidade de cuidado e proteção da família está diretamente relacionada ao cuidado e à proteção que lhe são garantidos através das políticas sociais, especialmente das políticas públicas. Nessa perspectiva a família na sociedade brasileira hoje, mais que ser reconhecida como instância de cuidado e proteção, deve ser reconhecida como instância a ser cuidada e protegida, enfatizando a responsabilidade pública.

Isso posto, percebe-se dois problemas: a desresponsabilização do Estado e terceirização dessa responsabilidade às famílias. O Estado, portanto, reconhece a família como base da sociedade e lhe concede proteção especial, entretanto "tal proteção tem sido cada vez mais discutida, à medida em que a realidade tem dado sinais cada vez mais evidentes de processos de penalização e desproteção das famílias” (MIOTO, 2004, p. 3).

Em relação à política social, a Lei Orgânica da Assistência Social, entre os objetivos expostos no art. $2^{\circ}$, encontra-se a I) proteção social, especialmente “a) a proteção à família, à maternidade, à infância, à adolescência e à velhice". A LOAS prevê o Benefício de Prestação Continuada enquanto uma de suas políticas no art. 20, da qual faz uso de um conceito de família.

Art. 20. O benefício de prestação continuada é a garantia de um saláriomínimo mensal à pessoa com deficiência e ao idoso com 65 (sessenta e cinco) anos ou mais que comprovem não possuir meios de prover a própria manutenção nem de tê-la provida por sua família.

§ 1 Para os efeitos do disposto no caput, a família é composta pelo requerente, o cônjuge ou companheiro, os pais e, na ausência de um deles, a madrasta ou o padrasto, os irmãos solteiros, os filhos e enteados solteiros e os menores tutelados, desde que vivam sob o mesmo teto. ${ }^{8}$ (BRASIL, 1993, grifos do original)

O conceito é bem restritivo ainda ao modelo nuclear, ainda que se refira às famílias recompostas. Embora desconsidere arranjos como de avôs/ós que tutelam netos/as, por exemplo, a proposta conceitual abrange os arranjos familiares predominantes na Pesquisa Nacional por Amostra de Domicílios 2001-2009 realizada pelo Instituto Brasileiro de Geografia e Estatística (IBGE), no ano de 2009. Essa pesquisa identificou que 47,3\% das famílias são formadas por casal com filhos, enquanto que a mulher sem conjugue com filhos e casais sem filhos têm cada $17,4 \%$, e por fim, $11,5 \%$ se refere à família unipessoal.

\footnotetext{
${ }^{8}$ Redação dada pela Lei no 12.435 , de 2011
}

Vol. 03, N. 10, Abr. - Jun., 2020 - http://periodicoscientificos.ufmt.br/ojs/index.php/rebeh/index 


\section{员드탠}

A assistência social, junto com a saúde e a previdência social, compõem o núcleo da Seguridade Social, conforme a Constituição Federal de 1988, art. 194. A Lei 8.112, de 1990, que "dispõe sobre o regime jurídico dos servidores públicos civis da União, das autarquias e das fundações públicas federais", prevê em seu art. 183 (da seguridade do servidor), que "A União manterá Plano de Seguridade Social para o servidor e sua família" (BRASIL, 1990, s/p). Assim,

Art. 184. O Plano de Seguridade Social visa a dar cobertura aos riscos a que estão sujeitos o servidor e sua família, e compreende um conjunto de benefícios e ações que atendam às seguintes finalidades:

I - garantir meios de subsistência nos eventos de doença, invalidez, velhice, acidente em serviço, inatividade, falecimento e reclusão;

II - proteção à maternidade, à adoção e à paternidade;

III - assistência à saúde. (BRASIL, 1990, s/p)

No texto constitucional disposto no título VIII, capítulo 2 - Da seguridade social, a seção III cuida da previdência social. Conforme o art. 201, o Regime Geral de Previdência Social atenderá a "II - proteção à maternidade, especialmente à gestante", "IV - salário-família e auxílio-reclusão para os dependentes dos segurados de baixa renda" e "V - pensão por morte do segurado, homem ou mulher, ao cônjuge ou companheiro e dependentes" (BRASIL, 1988).

Cronemberger e Teixeira (2011, p. 3), em estudo sobre a centralidade da família nas políticas sociais de atenção básica, incluídas as de saúde, identificam que

No que se refere à Política da Saúde, a família aparece como categoria importante a partir do estabelecimento de estratégias de saúde preventiva com o PSF. Esse Programa reorienta o foco da saúde, que passa da doença de um indivíduo, em geral entendido fora de seu contexto social e econômico, para a família.

Há uma equação de poder entre o Estado, a família e o Direito. O casamento é uma forma privilegiada de família que se fecha no modelo nuclear. Essa forma é legitimada pelo Estado que, embora reconheça novos arranjos, continua a prevalecer o casamento sobre demais arranjos e possibilidades de se constituir famílias. Isso impacta, sobremaneira, no acesso às políticas sociais, que, como visto, são marcadas por esse ‘familismo jurídico'. 
O Estado se utiliza da família para estabelecer direitos e terceirizar o bem-estar e acesso às políticas públicas, denotando o familismo denunciado por Sunkel (2006). A família é lugar de acesso a direitos e bens sociais, embora há que se questionar a qualidade e eficiência das políticas sociais brasileiras que tem sobrecarregado as famílias, sobretudo, aquelas com menos poder econômico.

\section{A LUTA POR RECONHECIMENTO DE CASAIS GAYS-LÉSBICOS E A JUDICIALIZAÇÃO DA FAMÍLIA}

Este tópico objetiva demonstrar (a) o processo histórico de luta em torno dos direitos matrimoniais e as disputas com o fundamentalismo religioso no âmbito da política institucional, que (b) culmina na judicialização da família com fins a satisfazer o reconhecimento sociojurídico dos casais gays-lésbicos.

\subsection{As disputas e tensões na arena política}

Os direitos de populações subjugadas existem em função da organização política e social que demandam seus devidos reconhecimentos jurídicos e sociais. Historicamente os movimentos de minorias sexuais e de gênero demandam igualdade no ordenamento jurídico. $\mathrm{O}$ direito à identidade de gênero, matrimônio igualitário e criminalização da homofobia são pautas históricas do ativismo LGBTI.

No Brasil, o ativismo LGBTI organizado surge na ditadura militar em fins da década de 1970. Naquele período os homossexuais são considerados como subversivos, ameaçadores da ordem, da moral e dos bons costumes (GREEN; QUINALHA, 2015). Desde esse momento, portanto, o movimento homossexual - como ficou conhecido à época - se insere na arena política para disputar a política e o direito.

Em 1980, com a epidemia HIV/Aids, o movimento viu-se frente a um paradoxo cujo estigma recai, sobretudo, em gays, mas que acompanha certa visibilidade política. Com o processo constituinte e a chegada dos anos 1990, a militância homossexual se insere na arena política mais incisivamente na vindicação de direitos. 


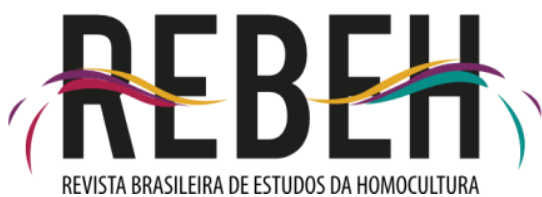

Em meados da década de 1990, dois pioneiros projetos foram submetidos ao Congresso Nacional, quais sejam: o PL n ${ }^{\circ} 1.151$ de 1995 - que buscava disciplinar a união civil entre pessoas do mesmo sexo - e o PL 70 de 1995 - que dispunha sobre a alteração do prenome mediante autorização judicial nos casos em que havia intervenção cirúrgica destinada a alterar o sexo.

O primeiro projeto submetido à Câmara Legislativa nacional acerca do direito à família buscava disciplinar a união civil, que se trata de "nova" categoria jurídica para afastar qualquer semelhança com os direitos de família como casamento, união estável e entidade familiar (MELLO, 2005). No substitutivo, o termo foi substituído por parceria civil registrada e ganhou dispositivo específico para vedar a possibilidade de parentalidade - adoção, tutela ou guarda de crianças/adolescentes ainda que filhos.

Além desse projeto, existem outros diversos que tramitaram no Congresso Nacional. Na Câmara de Deputados, têm-se:

a) PL 580/2007, de autoria de Clodovil Hernandes - PTC, que tinha por objetivo alteração do Código Civil para dispor sobre o contrato civil de união homoafetiva;

b) PL 4914/2009, de Jose Genuíno - PT, altera o Código Civil para aplicação dos dispositivos da união estável à união entre pessoas do mesmo sexo;

c) PL 5167/2009, de Capitão Assumção - PSB, altera Código Civil para garantir que relações entre pessoas do mesmo sexo não sejam equiparadas ao casamento e união estável, advogando pela "família tradicional”;

d) PL 5120/2013, de Jean Wyllys - PSOL, altera o Código Civil para reconhecer o casamento civil e união estável entre pessoas do mesmo sexo;

e) PL 6583/2013, de Anderson Ferreira - PR, dispõe sobre o Estatuto da Família e dá outras providências;

No Senado Federal há o PL 612/2011, de Marta Suplicy - PT, com objetivo de alterar o Código Civil parar reconhecer união estável entre pessoas do mesmo sexo.

Nenhum projeto com fins a aprovação de direitos LGBTI de qualquer natureza fora aprovado nas dependências do Poder Legislativo. Todas tentativas e articulações 
restaram infrutíferas. As maiores dificuldades podem ser atribuídas às disputas e tensões entre o ativismo LGBTI e o fundamentalismo religioso ${ }^{9}$ institucionalizado.

De acordo com Machado e Picollo (2010, p. 171), “o campo da religião é tradicionalmente compreendido como uma arena de normas e prescrições morais, na qual a sexualidade está incluída". Desse modo, "diante dessas novas configurações matrimoniais e familiares, muitas vezes têm surgido fortes reações, geralmente fundadas em bases religiosas, como defensoras da família 'verdadeira', 'legítima', 'sagrada' e 'natural"' (MELLO, 2005, p. 39).

Natividade e Oliveira (2013, p. 101), em estudos sobre poder religioso no Brasil ${ }^{10}$, constaram que há “o endosso da concepção do matrimônio como parte do 'plano de Deus' para o relacionamento entre homens e mulheres", tencionando, portanto, que o matrimônio é um direito divino, não civil. A sexualidade historicamente é regulada pela religiosidade que no cenário atual preza pela manutenção de seu poder.

Os projetos de lei no Congresso Nacional, com exceção ao PL 5167/2009 e PL 6583/2013, possuem objetivos e finalidades aproximadas, qual seja: conferir amparo legal às uniões com fins a constituir família formadas por pessoas do mesmo sexo. Não possuem grandes divergências entre si, nem propõem avançar além do modelo de família nuclear hegemônico consagrado, pautado na monogamia, durabilidade e reprodução.

Mello (2005) evidencia que a constituição de parcerias afetivo-sexuais entre homossexuais desafia a norma vigente, embora gays e lésbicas, em geral, tem buscado espelhar suas experiências na conjugalidade nos parâmetros heterossexuais. Nesse caminho, Butler (2003) compreende o parentesco e casamento são objetos de intensa vigilância do Estado que reduz o campo da sexualidade ao casamento.

As demandas pela família condicionam o debate à aquisição de legitimidade que se traduz em um processo de normalização. O casamento é uma norma que prolonga as

\footnotetext{
${ }^{9}$ Lionço (2017) aponta que é uma força política que busca defender os valores tradicionais da família heterossexual monogâmica visto a decência da prática sexual restrita à família e reprodução. O fundamentalismo religioso possui diversas facetas e possui como eixo central a ofensiva contra direitos de LGBTI e mulheres.

${ }^{10} \mathrm{O}$ autor deste trabalho publicou resenha da obra em debate na Revista Brasileira de Estudos da Homocultura. Para ver mais: OLIVEIRA, B. A. As Novas Guerras Sexuais: Diferença, Poder Religioso e Identidades LGBT no Brasil. Disponível em: https://periodicoscientificos.ufmt.br/ojs/index.php/rebeh/article/view/9942. Acesso em: 10/08/2020.
}

Vol. 03, N. 10, Abr. - Jun., 2020 - http://periodicoscientificos.ufmt.br/ojs/index.php/rebeh/index 


\section{员드탠}

relações de propriedade e torna conservadora as formas sociais de sexualidade (BUTLER, 2003). Dentro dos limites inteligíveis, as expressões sexuais fora dos limites do casamento já estão, em maior ou menor grau, fora da norma.

O Estado tem o monopólio sobre o "controle hegemônico das normas de reconhecimento" e se "tornar reconhecível dentro das normas existentes de legitimidade requer que aprovemos uma prática que deslegitima aquelas vidas sexuais estruturadas fora dos vínculos do casamento e das pressuposições de monogamia" (BUTLER, 2003, p. 239). Em outras palavras, "é deslocar o espaço de deslegitimização de uma parte da comunidade gay para outra, ou, mais ainda, é transformar uma deslegitimização coletiva em uma deslegitimização seletiva" (BUTLER, 2003, p. 240).

Pautando-se nas discussões acima, a luta por reconhecimento LGBTI nas questões de família é multifacetada. Em um contexto de violência em decorrência da orientação sexual e/ou identidade de gênero, a luta por reconhecimento pode se confundir com uma busca pela normalização e legitimidade, uma vontade de transitar da marginalidade à hegemonia das relações afetivo-sexuais.

As demandas pelo legislativo ou pelo judiciário também confirmam que a comunidade LGBTI, na busca pelo direito a constituir família, se apropriou do paradigma jurídico existente, tomando os moldes da família heterossexual, monogâmica e reprodutiva como modelo de família.

Por outro lado, "a formação de sentidos e práticas familiares nos modos de vida de homossexuais é parte um complexo processos social e cultural" (VESPUCCI, 2014, p. 38, tradução nossa) ${ }^{11}$. Dessa forma, é compreensível, em certa medida, o desejo em se tornar norma. Isso leva a compreender a ampliação do direito de família em termos de cidadania homossexual e direitos humanos, na qual, a sociedade tem uma dívida com os grupos minoritários sexuais por negar-lhes direitos e legitimidade.

Além disso, conforme a discussão realizada no título anterior, a força ideológica da cultura conjugal é mais que uma necessidade alimentada socialmente de uma vida de casal, sendo também um condicionador de acesso a direitos e bens sociais.

11 “[...] la formación de sentidos y prácticas familiares en los modos de vida homosexuales es parte de un complejo proceso social y cultural" (VESPUCCI, 2014, p. 38).

Vol. 03, N. 10, Abr. - Jun., 2020 - http://periodicoscientificos.ufmt.br/ojs/index.php/rebeh/index 


\subsection{A judicialização da homoconjugalidade}

As disputas políticas entre o conservadorismo religioso e ativismo LGBTI acabou por não aprovar nenhuma legislação específica protetiva acerca da diversidade sexual e de gênero. Não que o legislativo seja inerte como diversos sujeitos apontam, pelo contrário, se movimenta, mas em sentido contrário a extensão de direitos à comunidade LGBTI, dadas as forças institucionais conservadoras, como a Frente Parlamentar Evangélica, que atua pela manutenção dos preceitos morais cristãos inscritos na ordem legal do país.

Esse cenário levou a comunidade LGBTI ajuizar inúmeras ações requerendo o reconhecimento de suas relações afetivo-sexuais, bem como direitos de outras ordens. Assim, os tribunais brasileiros tiveram que se posicionar acerca da temática. Em maio de 2011, em decisão da Ação Direta de Inconstitucionalidade (ADI) 4.277 e Arguição de Descumprimento de Preceito Fundamental (ADPF) 132/RJ, o Supremo Tribunal Federal reconheceu a união estável entre pessoas do mesmo sexo, portanto, admitida como entidade familiar e com todos efeitos daquela prevista para casais heterossexuais.

A ADI 4.277 buscava o reconhecimento da união entre pessoas do mesmo sexo como entidade familiar, pedindo que os direitos e deveres da união estável fossem estendidos aos casais homossexuais, enquanto que a ADPF 132 alegava que não reconhecer a união entre pessoas do mesmo sexo contraria preceitos fundamentais como igualdade, liberdade, dignidade da pessoa humana, solicitando que o regime das uniões estáveis fosse aplicado às uniões homossexuais. A ADPF perdeu parcialmente seu objeto e a parte remanescente fora recebida pela ADI.

Conforme se extrai do acordão publicado, primeiramente a discussão se passa pela proibição de discriminação de pessoas em razão do sexo - tanto em relação ao gênero, quanto à orientação sexual - visto que não se presta como vetor de desigualdade jurídica, além de que promover o bem de todos é um objetivo constitucional.

Reconhece o direito para dispor da própria sexualidade como um direito fundamental, o direito à felicidade e a autonomia de vontade. Passando ao tratamento 


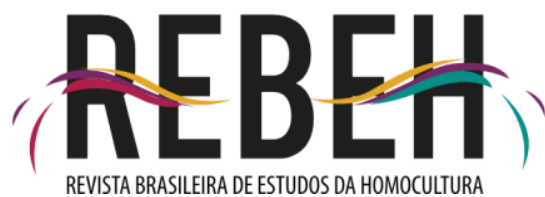

constitucional da Família, apontam que o termo não possui significado ortodoxo no texto magno, o direito subjetivo a constituir família e a interpretação não-reducionista.

Quanto ao objeto, qual seja, a união estável, reconhecem que a Constituição ao se referir a homem e mulher possui o propósito de promover relações jurídicas horizontais e sem hierarquias entre o binômio de gênero, como um reforço ao combate à cultura patriarcal dos costumes brasileiros.

Por fim, utiliza-se da técnica da interpretação conforme para interpretação do art. 1.723 do Código Civil em conformidade com a Constituição, reconhecendo a união homoafetiva como família. Ressalte-se que em âmbito de divergências, três ministros convergiram no sentido de que a união homoafetiva é uma nova forma de entidade familiar, não se enquadrando enquanto uma das espécies constitucionais.

No mês de outubro do mesmo ano, em julgamento do Recurso Especial (REsp) 1.183.378/RS, o Superior Tribunal de Justiça admitiu o casamento civil entre pessoas do mesmo sexo, acompanhando o STF na decisão sobre a união estável. A ação discutia os dispositivos civis e constitucionais que facilitam a conversão da união estável em casamento, direito que foi negado a um casal de lésbicas do Rio Grande do Sul pelos cartórios e sistema de justiça de $1^{\mathrm{a}}$ e $2^{\mathrm{a}}$ instância, recaindo ao STJ.

Embora o direito a constituir família fora reconhecido tanto pelo STF, quanto pelo STJ, em 2013, o Conselho Nacional de Justiça (CNJ) teve editar uma resolução que vedava as autoridades competentes de recusar habilitação, celebração de casamento civil ou de conversão de união estável em casamento entre pessoas do mesmo sexo. Àquela altura, denúncias de que órgãos cartoriais estariam se recusando a realizar os devidos registros chegaram ao $\mathrm{CNJ}$.

Esse fato revela a precariedade jurídica que a comunidade LGBTI está submetida. Mesmo que reconheça direitos por via da judicialização, não significa acesso e efetividade. Atualmente a identidade de gênero, criminalização da homofobia, doação de sangue, adoção, união estável e casamento, além da não-discriminação por orientação sexual e gênero, são direitos reconhecidos pelo sistema de justiça brasileiro. Todavia, não são raras as denúncias de hemocentros se recusam a receber sangue de gays, que a 


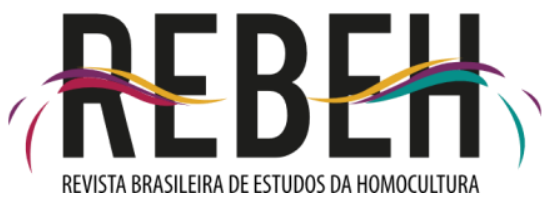

identidade de gênero não é respeitada no sistema de serviços de públicos, além da subnotificação dos crimes de LGBTIfobia que são caracterizados como crimes comuns.

Os direitos civis (incluídos os de família) são vetores de acesso aos direitos de ordem não apenas no campo civil, alcançando também direitos sociais, como o tripé da seguridade social. Inclusive, Leal e Oliveira (2020) identificam que o direito à identidade de gênero é vetor de acesso ao emprego e trabalho decente.

Acerca das uniões conjugais, não seria diferente, como se viu anteriormente, a família é central no ordenamento jurídico brasileiro e possibilita acesso aos direitos e políticas de proteção social. Tanto que, nos anos 2000, o Ministério Público Federal, com apoio de entidades e grupos pela diversidade sexual, ajuizou Ação Civil Pública em face do Instituto Nacional de Seguridade Social (INSS).

A ação discutia a consideração de companheiros/as homossexuais como dependentes preferenciais na mesma classe dos heterossexuais conforme art. 15, I, da lei 8.212/1991, para fins de concessão de benefícios previdenciários, deferindo os de pensão por morte e auxilio-reclusão a eles relacionados, assim como a possibilidade de inscrição de companheiros/as como dependentes inclusive nos casos de segurado empregado ou trabalhador avulso. O INSS fora condenado da $1^{\text {a }}$ instância ao STJ, assim, apesar dos recursos, o Poder Judiciário posicionou-se pela procedência da ação.

Essa judicialização logo no início dos anos 2000 demonstra que o ativismo LGBTI priorizou acessar os direitos sociais e, embora já se discutia na arena política o direito à união homossexual, a judicialização da previdência adveio antes mesmo de reconhecer os direitos de família que possibilitariam a inscrição de companheiros/as homossexuais como dependentes preferenciais no Regime Geral de Previdência.

E no cenário latino-americano, fundando nas desigualdades socioeconômicas, o acesso aos direitos civis significa uma possibilidade de efetivar a justiça social, uma vez

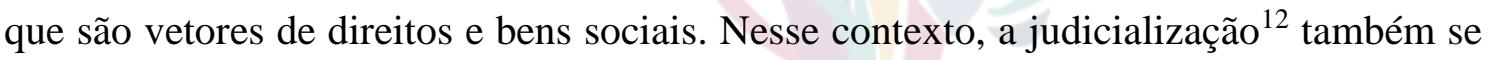
torna um instrumento capaz de promoção de justiça social, uma vez que

\footnotetext{
${ }^{12}$ A temática da judicialização remonta o tema da expansão da jurisdição constitucional. Com a $2^{\mathrm{a}}$ Guerra Mundial viu-se a necessidade de um Poder Judiciário forte e independente como um elemento essencial as democracias modernas dada a necessidade de preservação de direitos fundamentais e do próprio Estado de
}

Vol. 03, N. 10, Abr. - Jun., 2020 - http://periodicoscientificos.ufmt.br/ojs/index.php/rebeh/index 
Judicialização significa que questões relevantes do ponto de vista político, social ou moral estão sendo decididas, em caráter final, pelo Poder Judiciário. Trata-se, como intuitivo, de uma transferência de poder para as instituições judiciais, em detrimento das instâncias políticas tradicionais, que são o Legislativo e o Executivo. (BARROSO, 2017, p. 2178)

A judicialização acaba por ser um desdobramento do desenho institucional adotado pelas democracias ocidentais. Na América Latina, constituída pela colonização, ditaduras e democracias fragilizadas, a população se apropria dos direitos fundamentais e humanos, inscritos em Constituições e Convenções Internacionais de Direitos Humanos, e o judiciário acaba por se tornar uma estratégia para conquista, garantia e efetivação desses direitos.

Uma corrente que, de certa forma, é conservadora aos impactos da judicialização, tem apontado para a noção de ativismo judicial. Via de regra, essa participação mais ampla do judiciário se dá em contextos de retração do poder legislativo, resistência em cumprimento efetivos de demandas e direitos sociais, ou pela necessidade de avançar em temas que não se consegue fazer pela via política majoritária. Todavia, o termo ativismo é insuficiente para a compreensão da questão (BARROSO, 2017).

Embora possa surgir comportamentos inapropriados, quando juízes/as deixam de aplicar o direito vigente a fim de promover os próprios valores, crenças ou preferências políticas, a judicialização tem se colocado como ferramenta virtuosa de assegurar direitos humanos e fundamentais, como em temáticas feministas e LGBTI.

É nesse ponto que se revela o papel contramajoritário do Poder Judiciário, uma vez que os direitos fundamentais, a proteção democrática e participação política de todos/as não podem estar sujeitos à política majoritária. Há ainda a possibilidade de invalidar atos que não estejam em compatibilidade com a Constituição, por intermédio do controle de constitucionalidade (BARROSO, 2017).

Igualdade, liberdade e dignidade humana são valores fundamentais do Estado Democrático de Direito, no qual a "democracia, portanto, para além da dimensão procedimental de ser o governo da maioria, possui igualmente uma dimensão substantiva, que inclui igualdade, liberdade e justiça” (BARROSO, 2017, 2198).

Direito. No pós-guerra firma-se a ideia de uma Constituição dotada de supremacia, definindo direitos humanos e fundamentais, e prevendo o controle de constitucionalidade a cargo de uma Suprema Corte.

Vol. 03, N. 10, Abr. - Jun., 2020 - http://periodicoscientificos.ufmt.br/ojs/index.php/rebeh/index 


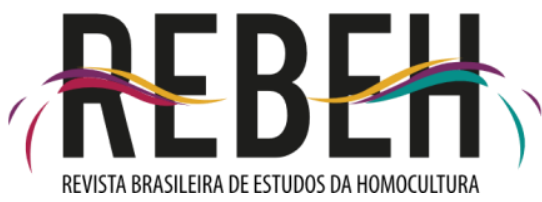

Vianna, Burgos e Salles (2007) apontam que as avaliações sobre pretensões de ativismo judicial são apressadas. Para os autores, não é uma escolha do judiciário avançar sobre domínios anteriormente ocupados por outras forças, tendo em vista que fora o constituinte que instituiu e dotou de competências o Poder Judiciário a fim de resolver conflitos políticos e sociais. O estudo nota que

[...] a invasão do direito sobre o social avança na regulação dos setores mais vulneráveis, em um claro processo de substituição do Estado e dos recursos institucionais classicamente republicanos pelo judiciário, visando a dar cobertura à criança e ao adolescente, ao idoso e aos portadores de deficiência física. O juiz torna-se protagonista direto da questão social. Sem política, sem partidos ou uma vida social organizada, o cidadão volta-se para ele, mobilizando o arsenal de recursos criado pelo legislador a fim de lhe proporcionar vias alternativas para a defesa e eventuais conquistas de direitos. (VIANNA; BURGOS; SALLES, 2007, p. 41)

Na esteira da questão social, Aguinsky e Alencastro (2006, p. 25) compreendem que essa tendência em transferir para o judiciário a responsabilidade por atendimento de demandas populares judicializadas em regra individualmente "ao invés de fortalecer a perspectiva de garantia de direitos positivados, pode contribuir para a desresponsabilização do Estado, sobretudo dos Poderes Legislativo e Executivo, com a efetivação destes direitos, através das políticas públicas".

Resta-se frente ao problema institucional brasileiro: uma população extremamente desigual em uma diversidade de sentidos para além do critério unicamente econômico, ciente de seus direitos humanos e fundamentais de diversas ordens - do civil ao social quando não cumpridos pelos poderes políticos, recorrem à judicialização como solução para garantia de direitos. Não poderia o Poder Judiciário, sobretudo o STF como guardião da Constituição, se omitir de sua função primordial: a promoção da justiça.

Nesse interim, a jurisdição constitucional quando exercida corretamente é mais uma garantia o jogo democrático do que uma ameaça. Entretanto, "a importância da Constituição - e do Judiciário como seu intérprete maior - não pode suprimir, por evidente, a política, o governo da maioria, nem o papel do Legislativo" (BARROSO, 2012, p. 28).

A Constituição possui um papel central na proteção dos direitos e valores fundamentais, independente do poder político majoritário e dos governos, isso é inclusive 


\section{苜ᄃBE吕}

garantir aquilo que Hesse (1991) nomeou de "a força normativa da Constituição". A expansão do judiciário e essa atuação progressista no reconhecimento de direitos fundamentais, em grande medida, tem se colocado mais como solução do que como problema, apesar das objeções e possíveis equívocos,

[..] é um antibiótico poderoso, cujo uso deve ser eventual e controlado. Em dose excessiva, há risco de se morrer da cura. A expansão do Judiciário não deve desviar a atenção da real disfunção que aflige a democracia brasileira: a crise de representatividade, legitimidade e funcionalidade do Poder Legislativo. Precisamos de reforma política. E essa não pode ser feita por juízes. (BARROSO, 2012, p. 32).

A inserção de pautas LGBTI na política majoritária enfrenta resistência da moralidade pública e fundamentalismos religiosos, quando não são utilizadas como moeda de troca com conservadores, como à época dos governos petistas, fragilizando as políticas públicas de direitos humanos LGBTI.

O debate no Poder Legislativo tem optado por caminhar em sentido contrário às aprovações e ao vanguardismo jurídico, e essa postura tem garantido nichos eleitorais aos conservadores que, inclusive, propõe projetos anti-LGBTIs e anti-feministas, como o Estatuto da Família e a (re)criminalização de abortos legais.

A judicialização até o momento foi a estratégia capaz de conquistar direitos para a comunidade LGBTI. Esse fenômeno e a luta por reconhecimento é plurifacetada. Há uma busca por legitimidade e direitos atravessada pela cultura conjugal e heteronormatividade, embora também há grupos questionando essa normalização. Portanto, o direito de família pode ser lido como cidadania sexual e direito fundamental disponível àqueles/as que dele querem fazer uso.

\section{CONSIDERAÇÕES FINAIS}

O cenário é delimitado por um ativismo LGBTI em constantes disputas, sejam elas internas, com o Estado e/ou com o fundamentalismo religioso, que vai das instituições democráticas à mídia hegemônica. O Brasil é um dos países que mais violentam e assassinam pessoas LGBTI no globo, embora não há dados oficiais acerca dessa violência. A negação de direitos de qualquer natureza tem um impacto profundo nessa comunidade. 


\section{REBE员}

Após longos e intensos períodos de ditadura militar na restrição dos direitos somada a um contexto constituído sob o prisma das assimetrias de poder e acesso aos bens sociais, as redemocratizações e novas Constituições da América Latina são orientadas pela necessidade tanto de fortalecimento do Estado de Direito, quanto pelo combate das desigualdades de diversas naturezas, como gênero, sexualidade, raça e classe.

Esse contexto histórico e político coincide com a expansão da jurisdição constitucional, ao qual advém da constitucionalização abrangente que acabam por se tornar pretensões jurídicas concretas na forma de judicialização, transferindo ao Poder Judiciário a resolução de conflitos sociais e políticos. Entretanto, não se pode atribuir postura deliberada ao judiciário, mas sim discutir efetivamente esse problema como resultado da não distribuição real e igualitária de poder na democracia liberal.

A família é objeto de disputas e atualmente encontra-se no cerne da política conservadora e dos pânicos morais, embora juridicamente o caminho tem apontado para a proteção plural dos arranjos. Essa instituição, consolidada historicamente, ocupa centralidade no direito, seja pela força ideológica da cultura conjugal, por questões de propriedade, pelas tradições religiosas ou pela socialização de pessoas, dado que é também instância fundamental para a reprodução da ordem social.

A comunidade LGBTI requerer o direito de família pode ser explicado de variadas formas, dado seu aspecto multifacetado. Socialmente a família e o casamento ocupam espaço privilegiado, e com a força da cultura conjugal, todos/as pessoas são orientadas à reprodução da família como realização pessoal e obrigação social. Constituir uma família para pessoas LGBTI pode significar respeito, ascensão e legitimidade social. Tanto que as pautas de família integram o leque das primeiras reivindicações do movimento nacional e internacional.

Todavia, também pode ser denunciado como normalização e cooptação de pessoas LGBTI para reprodução da cultura hegemônica e conservadora, dado que os moldes da família nuclear se baseiam na heteronormatividade que se caracteriza como monogâmica, reprodutiva e heterossexual, além do sexismo, que eleva o masculino em detrimento do feminino. 
Num contexto de LGBTfobia estrutural e de assimetrias políticas, econômicas e sociais, o direito civil, incluso os de família, são vetores de acesso a bens e direitos sociais, como é o caso do tripé da seguridade social. Ou seja, é a possibilidade de uma vida com melhores condições e dignidade. Frente ao familismo do ordenamento jurídico e das políticas sociais, o direito a constituir família se coloca como uma condição material básica para aqueles/as que dele querem usufruir.

\section{REFERÊNCIAS}

AGUINSKY, Beatriz Gershenson; ALENCASTRO, Ecleria Huff de. Judicialização da questão social: rebatimentos nos processos de trabalho dos assistentes sociais no Poder Judiciário. Rev. katálysis, Florianópolis, v. 9, n. 1, p. 19-26, June 2006 . Available from <http://www.scielo.br/scielo.php?script=sci_arttext\&pid=S1414$49802006000100002 \& \operatorname{lng}=$ en\&nrm=iso $>$.

access on 22 July 2019. http://dx.doi.org/10.1590/S1414-49802006000100002.

ARIÈS, Philippe. História Social da Criança e da Família. 2a ed. Rio de Janeiro: LTC, 1981.

BARROSO, Luís Roberto. Contramajoritário, Representativo e Iluminista: Os papeis dos tribunais constitucionais nas democracias contemporâneas. Revista Direito e Práxis, [S.1.], v. 9, n. 4, p. 2171-2228, dez. 2018. ISSN 2179-8966. Disponível em: <https://www.e-publicacoes.uerj.br/index.php/revistaceaju/article/view/30806>. Acesso em: 22 jul. 2019.

BARROSO, Luís Roberto. Judicialização, ativismo judicial e legitimidade democrática. (SYN) THESIS, 2012, v. 5, n. 1. ISSN 2358-4130. Disponível em: < https://www.epublicacoes.uerj.br/index.php/synthesis/article/view/7433>. Acesso em 16 jan. 2019.

BRASIL. CÂMARA DOS DEPUTADOS. Projeto de lei $\mathbf{n}^{\circ} \mathbf{1 . 1 5 1}$, de 1995. Disciplina a união civil entre pessoas do mesmo sexo e dá outras providências. Disponível em: http://www.camara.gov.br/proposicoesWeb/fichadetramitacao?idProposicao $=16329$.

Acesso em: 22 jul. 2020.

BRASIL. CÂMARA DOS DEPUTADOS. Projeto de lei $\mathbf{n}^{\mathbf{0}} \mathbf{4 . 9 1 4}$, de 2009. Altera a Lei $\mathrm{n}^{\mathrm{o}}$ 10.406, de 10 de janeiro de 2002 - Código Civil. Disponível em: http://www.camara.gov.br/proposicoesWeb/fichadetramitacao?idProposicao=427692. Acesso em: 22 jul. 2020.

BRASIL. CÂMARA DOS DEPUTADOS. Projeto de lei $\mathbf{n}^{\circ}$ 5.120, de 2013. Altera os arts. $551,1.514,1.517,1.535,1.541,1.565,1.567,1.598,1.642,1.723$ e 1.727 da Lei ${ }^{\circ}$ 10.406 de 10 de janeiro de 2002, para reconhecer o casamento civil e a união estável entre pessoas do mesmo sexo. Disponível em: http://www.camara.gov.br/proposicoesWeb/fichadetramitacao?idProposicao $=567021$. Acesso em: 22 jul. 2020.

Vol. 03, N. 10, Abr. - Jun., 2020 - http://periodicoscientificos.ufmt.br/ojs/index.php/rebeh/index 
BRASIL. CÂMARA DOS DEPUTADOS. Projeto de lei no 5.167, de 2009. Altera o art. 1.521 da Lei $n^{\circ}$ 10.406, de 10 de janeiro de 2002, que institui o Código Civil. 2009. Disponível em: https://www.camara.leg.br/proposicoesWeb/fichadetramitacao?idProposicao=432967. Acesso em: 22 jul. 2020.

BRASIL. CÂMARA DOS DEPUTADOS. Projeto de lei $\mathbf{n}^{\mathbf{0}} \mathbf{5 8 0}$, de 2007. Altera a Lei $\mathrm{n}^{\circ} 10.406$, de 10 de janeiro de 2002 - Código Civil, para dispor sobre o contrato civil de união homoafetiva. Disponível em: http://www.camara.gov.br/proposicoesWeb/fichadetramitacao?idProposicao=346155. Acesso em: 22 jul. 2020.

BRASIL. CÂMARA DOS DEPUTADOS. Projeto de lei $\mathbf{n}^{\mathbf{0}}$ 6.583, de 2013. Dispõe sobre o Estatuto da Família e dá outras providências. Disponível em: http://www.camara.gov.br/proposicoesWeb/prop_mostrarintegra?codteor $=1159761 \&$ fil ename $=P L+6583 / 2013$. Acesso em: 22 jul. 2020.

BRASIL. CÂMARA DOS DEPUTADOS. Projeto de lei $\mathbf{n}^{\mathbf{0}} \mathbf{7 0}$, de 1995. Dispõe sobre intervenções cirúrgicas que visem à alteração de sexo e dá outras providências. Disponível em: <https://www.camara.leg.br/proposicoesWeb/fichadetramitacao?idProposicao=15009>. Acesso em: 22 jul. 2020.

BRASIL. CONSELHO NACIONAL DE JUSTIÇA. Resolução $\mathbf{N}^{\mathbf{0}} \mathbf{1 7 5}$, de 14 de maio de 2013. Disponível em: http://www.cnj.jus.br/files/atos_administrativos/resoluo-n17514-05-2013-presidncia.pdf. Acesso em: 22 jul. 2020.

BRASIL. Constituição da República Federativa do Brasil. 1988. Disponível em: http://www.planalto.gov.br/ccivil_03/constituicao/constituicaocompilado.htm. Acesso em: 13 jan. 2018.

BRASIL. Decreto-Lei 2.848, de 07 de dezembro de 1940. Código Penal. Disponível em: http://www.planalto.gov.br/ccivil_03/decreto-lei/Del2848compilado.htm. Acesso em: 13 jan. 2018.

BRASIL. Lei $\mathbf{n}^{0} \mathbf{1 0 . 4 0 6}$, de 10 de janeiro de 2002. Institui o Código Civil. Disponível em: http://www.planalto.gov.br/ccivil_03/leis/2002/L10406.htm. Acesso em: 13 jan. 2018.

BRASIL. Lei n 8.112, de 11 de dezembro de 1990. Dispõe sobre o regime jurídico dos servidores públicos civis da União, das autarquias e das fundações públicas federais. Disponível em: http://www.planalto.gov.br/ccivil_03/leis/L8112cons.htm. Acesso em: 13 jan. 2018

BRASIL. Lei $\mathbf{n}^{\circ}$ 8.742, de 7 de dezembro de 1993. Dispõe sobre a organização da Assistência Social e dá outras providências. Disponível em: http://www.planalto.gov.br/ccivil_03/leis/18742.htm. Acesso em: 13 jan. 2018.

BRASIL. SENADO FEDERAL. Projeto de Lei do Senado $\mathbf{n}^{\mathbf{0}}$ 612, de 2011 (Casamento homoafetivo). Altera os art. 1.723 e 1.726 do Código Civil, para permitir o reconhecimento legal da união estável entre pessoas do mesmo sexo. Disponível em: 
https://www25.senado.leg.br/web/atividade/materias/-/materia/102589. Acesso em: 13 jan. 2018

BRASIL. SUPERIOR TRIBUNAL DE JUSTIÇA. RECURSO ESPECIAL No 1.183.378 - RS (2010/0036663-8). Disponível em: https://stj.jusbrasil.com.br/jurisprudencia/21285514/recurso-especial-resp-1183378-rs2010-0036663-8-stj/inteiro-teor-21285515. Acesso em: 08 jan. 2018

BRASIL. SUPREMO TRIBUNAL FEDERAL. AÇÃO DIRETA DE INCONSTITUCIONALIDADE 4.277 DISTRITO FEDERAL. Disponível em: http://redir.stf.jus.br/paginadorpub/paginador.jsp?docTP=AC\&docID=628635. Acesso em: 08 jan. 2018

BRASIL. TRIBUNAL REGIONAL DA $4^{\mathrm{a}}$ REGIÃO. Íntegra da decisão que obriga INSS a equiparar homossexuais e heterossexuais em todo o Brasil. 2005. Disponível em:

https://www.trf4.jus.br/trf4/controlador.php?acao=noticia_visualizar\&id_noticia=4719> . Acesso em: 08 jan. 2018.

BUDGEON, Shelley. Couple Culture and the Production of Singleness. Revista Sexualities, 2008, vol. 11, no. 3, pp. 301-325. Disponível em: < https://journals.sagepub.com/doi/10.1177/1363460708089422\#articleCitationDownload Container>. Acesso em: 08 jan. 2018.

BUTLER, Judith. O parentesco é sempre tido como heterossexual? Cadernos Pagu, 21, p. 219-260, 2003.

CRONEMBERGER, I. H. G. M.; TEIXEIRA, S. M. A centralidade da família nas políticas sociais de atenção básica: qual projeto e direção do trabalho social com famílias? 2011. Disponível em: http://www.joinpp.ufma.br/jornadas/joinpp2011/CdVjornada/EIXO_IMPASSES_E_DE SAFIOS_DAS_POLITICAS_DA_SEGURIDADE_SOCIAL.htm. Acesso em: 13 jan. 2018.

FOUCAULT, Michel. História da sexualidade I: A vontade de saber, tradução de Maria Thereza da Costa Albuquerque e J. A. Guilhon Albuquerque. Rio de Janeiro, Edições Graal, 1988.

GREEN, J. N; QUINALHA, R. Homossexualidade, Repressão e Resistência durante a Ditadura. 2015. Disponível em: http://www.cev-rio.org.br/site/arq/Green-J-eQuinalha-R-Homossexualidades-repressao-e-resistencia-durante-a-ditadura.pdf. Acesso em: 22 jul. 2020

HESSE, Konrad. A força normativa da Constituição. Tradução e notas de Gilmar Ferreira Mendes. Porto Alegre: Fabris, 1991.

HILLER, Renata. Regulaciones estatales de la conyagalidad: Apuntes sobre Estado, matrimonio y heteronormatividad. In: JONES, D.; FIGARI, C.; LÓPEZ, S. B. La producción de la sexualidad: políticas y regulaciones sexuales en Argentina. $1^{\mathrm{a}}$ ed. Buenos Aires: Biblos, 2012. 
IBGE. Pesquisa Nacional por Amostra de Domicílios 2001-2009. Disponível em: <https://seriesestatisticas.ibge.gov.br/>. Acesso em: 08/01/2018.

IRINEU, B. A. et al. "O samba começou e fez convite ao tango para parceiro"? A arena LGBTI em tempos de ofensiva neoliberal e "cruzada antigênero" no Brasil e na Argentina. Humanidades \& Inovação. 2019, v. 6, n. 17, p. 255-270. Disponível em: $<$ https://revista.unitins.br/index.php/humanidadeseinovacao/article/view/1802>. Acesso em 24 de junho de 2020.

IRINEU, B. A.; OLIVEIRA, B. A. Um balanço das políticas públicas de trabalho, emprego e renda para população LGBT no Brasil e na Argentina (2004-2014). Revista Direitos Humanos e Democracia, Ano 8, $\mathrm{n}^{\circ}$ 16, Jul./Dez. 2020. Disponível em: $<$ https://www.revistas.unijui.edu.br/index.php/direitoshumanosedemocracia>. Acesso em: 05 dez. 2020.

LEAL, Carla Reita Faria; OLIVEIRA, Brendhon Andrade. O direito à identidade de gênero e políticas públicas de trabalho: pela garantia do mínimo existencial para a população trans no Brasil. Revista BEJ, v. 15, n. 1 - Quadrimestral - Montes Claros, MG - jan./abr. 2020. Disponível em: <https://direito.fasa.edu.br/?/revista-bej/\#7>. Acesso em: 22 jul. 2020

LIONCO, Tatiana. Psicologia, Democracia e Laicidade em Tempos de Fundamentalismo Religioso no Brasil. Psicologia: Ciência e Profissão. 2017, vol.37, n.spe, pp.208-223.

MACHADO, Maria das Dores Campos; PICCOLLO, Fernanda Delvalhas. Religiões e homossexualidades. Rio de Janeiro: Editora FGV, 2010.

MELLO, Luiz. Novas famílias: Conjugalidade homossexual no Brasil contemporâneo. Rio de Janeiro: Garamond, 2005.

MEZZAROBA, Orides; MONTEIRO, C. S. Manual de metodologia da pesquisa no Direito. 4. Ed. São Paulo: Saraiva, 2010.

MIOTO, Regina Célia Tamaso. A centralidade da família na política de assistência social: contribuições para o debate. Revista de Política Pública. Maranhão: Universidade Federal do Maranhão, 2004.

NATIVIDADE, Marcelo; OLIVEIRA, Leandro de. As novas guerras sexuais: diferença, poder religioso e identidades LGBT no Brasil. 1. Ed. Rio de Janeiro: Garamond. 2013.

OLIVEIRA, B. A. As Novas Guerras Sexuais: Diferença, Poder Religioso e Identidades LGBT no Brasil. REBEH - Revista Brasileira de Estudos da Homocultura, Vol. 02, N. 01, Jan. - Mar., 2019, p. 254-259.

OLIVEIRA, B. A.; LEAL, C. R. F. Homoconjugalidade em Debate: Aproximações entre o Brasil e o Sistema Interamericano de Direitos Humanos. In: SOUZA, Carlos Eduardo Silva e; SANTOS, Julia Natália Araújo (Orgs.). Estudos de Direito Civil Contemporâneo. Rio de Janeiro: Lumen Juris, 2020, p. 337-375.

PRATES, Jane C.; PRATES, Flávio C. Problematizando o uso da técnica de Análise Documental no Serviço Social e no Direito. Sociedade em Debate, Pelotas, 15(2): 111125, jul.-dez/2009. 
RUBIN, Gayle. Pensando o sexo: Notas para uma teoria radical da política da sexualidade.

2012.

Disponível

em:

http://repositorio.ufsc.br/xmlui/handle/123456789/1582. Acesso em: 08 jan. 2018.

SUNKEL, G. El papel de la familia en la protección social. Santiago de Chile: Cepal, División de Desarollo Social, 2006. (Série Políticas Sociais, v. 120.)

VESPUCCI, G. Una fórmula deseable: el discurso "somos familias" como símbolo hegemónico de las reivindicaciones gay-lésbicas. Revista Latinoamericana Sexualidad, Salud y Sociedad [online]. 2014, n. 17, pp. 30-65. ISSN 1984-6487. Disponível em: < http://www.scielo.br/pdf/sess/n17/1984-6487-sess-17-0030.pdf>. Acesso em: 08 jan. 2018.

VIANNA, Luiz Werneck; BURGOS, Marcelo Baumann; SALLES, Paula Martins. Dezessete anos de judicialização da política. Tempo soc., São Paulo, v. 19, n. 2, Nov. 2007 .

\title{
CONJUGAL CULTURE, LEGAL FAMILY AND THE JUDICIALIZATION OF LGBTI RIGHTS IN BRAZIL
}

\begin{abstract}
The present study analyzes the process of recognition of the right to homoconjugality, through documentary analysis that selected legislative proposals and judicial sentences. The hypothetical-deductive method is used considering three main hypotheses: there is a centrality of the family in the Brazilian legal system; the struggle for recognition in matters of family is a search for legitimacy and also for access to goods and social rights; and the judicialization of the family remained as an alternative to legislative resistance in recognizing LGBTI rights. A bibliographic study was carried out based on legal, feminist, queer, gay and lesbian studies. Thus, it identifies that the desire to establish a family is complex and multifaceted, since there are social crossings through the conjugal culture, the centrality of the family in social protection policies and civil law as a vector of social rights, still facing conservative resistances in politics majority, resorting to judicialization as a strategy for legal recognition of gay-lesbian couples.
\end{abstract}

Keywords: Family Law; Marriage; Judicial power; Institutional Policy; Conservatism.

Recebido: 12/09/2020

Aceito: 17/12/2020

Vol. 03, N. 10, Abr. - Jun., 2020 - http://periodicoscientificos.ufmt.br/ojs/index.php/rebeh/index 